Acta Technologica Agriculturae 1

Nitra, Slovaca Universitas Agriculturae Nitriae, 2018, pp. 1-7

\title{
EFFECT OF VARYING PARBOILING CONDITIONS ON HEAD RICE YIELD FOR COMMON PADDY VARIETIES IN IRAN
}

\author{
Fatemeh RAHIMI-AJDADI ${ }^{1 *}$, Ezzatollah ASKARI ASLI-ARDEH ${ }^{2}$, Adel AHMADI-ARA ${ }^{2}$ \\ ${ }^{1}$ University of Guilan, Rasht, Iran \\ ${ }^{2}$ University of Mohaghegh Ardabili, Ardabil, Iran
}

\begin{abstract}
Various conditions of a parboiling process affect the qualitative parameters of paddy milling. In this study, the effects of drying temperature $\left(45\right.$ and $60^{\circ} \mathrm{C}$ ), moisture content $(8,10$ and $12 \%$ w.b.), steaming time (10, 20 and 30 min) and paddy varieties (Hashemi and Alikazemi) were investigated on head rice yield ( $H R Y$ ). The samples were husked using a rubber roller husker and whitened by a laboratory abrasive whitener. Results showed that the main effects of all parameters were significant on $H R Y(P<0.01)$. The utilization of higher temperature $\left(60^{\circ} \mathrm{C}\right)$, in comparison with non-parboiled rice, without reducing the milling quality was found as one of the advantages of parboiling. Among all experiments, the highest $H R Y(68.647 \%)$ was achieved in the combination of Alikazemi $/ 45^{\circ} \mathrm{C} / 10 \mathrm{~min} / 8 \%$. In the majority of cases, the combinations including Alikazemi variety had higher $H R Y$ than Hashemi. For Hashemi variety, the highest $H R Y(67.297 \%)$ was achieved in combination $45^{\circ} \mathrm{C} / 10 \mathrm{~min} / 8 \%$. In terms of $H R Y$, parboiling causes an increase of $25.8 \%$ and $43.3 \%$ respectively for Hashemi and Alikazemi. Therefore, it is highly recommended in processing of Alikazemi variety.
\end{abstract}

Keywords: drying temperature; steaming time; moisture content; milling; rice variety

Rice is one of the staple foods in Asia that provides a considerable part of energy intake of people. World rice production is approximately 618 million tons per year; about $50 \%$ of the production is under parboiling process. Paddy parboiling is carried out in many countries, including India, Bangladesh, Pakistan, Myanmar, Malaysia, Sri Lanka, Guinea, South Africa, Italy, Spain, Thailand, Switzerland, and France (Pillaiyar, 1981). The main reasons for impressive reception of the parboiled rice are the increase in grain strength (which increases the HRY and decreases the milling losses), enhancement of rice nutritional properties including vitamin B and minerals, especially phosphorus and potassium (up to 18\%), and increase in quality while in storage (Juliono, 1985; Chakraverty and Paul Singh, 2001). During the common milling stage (non-parboiled method), the bran surrounding the outer layer of brown rice is removed despite having nutrients. In the process of rice parboiling, the nutrients of the bran move to the grain centre and consequently enhance the grain quality. Considering its economic and nutritional benefits, the extension of this technology is essential in milling rice units, especially in developing countries where the rate of rice lost due to the old machinery is very high. In addition, the application of such technologies is essential for the rice self-sufficiency of these countries. The conventional method of parboiling includes three stages: soaking in water, steaming (to complete the gelatinization of starch) and drying. Surveying the optimal values for every the effective variable has significant impacts on the milling properties, as well as the energy consumption.
Many studies have been conducted in the field of parboiling that focused on several aspects, including developing parboiling systems, supplying and consuming energy in parboiling and optimizing the parboiling stages (Kwofie and Ngadi, 2017). Recently, for instance, a research group investigated the influence of soaking variables on parboiled rice quality (Da Fonseca et al., 2011). Another group surveyed the influence of soaking time on the crushing strength of raw parboiled rice and reported an inverse relationship (Jagtap et al., 2008). Oyedele and Adeoti (2013) found that a minimum breakage for rice kernel is obtained at the steaming time of 41.5 minutes and milling moisture content of $16 \%$. The parboiling efficiency of $95 \%$ and milling quality of $91 \%$ at $70^{\circ} \mathrm{C}$ soaking temperature and three hours of soaking time were reported as optimal conditions for parboiling by Imonigie et al. (2017). Considering the large diversity in parboiling variables and their effects on $H R Y$, further research on its different conditions is noteworthy, especially for popular varieties highly susceptible to breakage. Mostly, different combinations of the related variables provide different results.

Despite the mentioned reasons about the benefits of parboiling in the milling quality, it has not developed in Iran industries and there is no comprehensive research about its optimal conditions and effective approaches to it. However, the local-domestic characteristics, especially variety type may have a significant effect on the procedure. Hence, the objective of present study is to survey the efficiency level of parboiling on $H R Y$ and compare it for two studied varieties. In addition, another objective is to investigate the effects 
of certain parboiling parameters on $H R Y$ for two popular paddy varieties in Iran.

\section{Material and methods}

The varieties of Hashemi and Alikazemi were selected for the experiments because they are the most cultivated varieties of rice in northern Iran. Some their are given in Table 1.

At first, the grains were manually cleaned from foreign materials. The initial moisture content was calculated according to ASAE standard (2000). Three paddy samples of $10 \mathrm{~g}$ were placed into an oven heated to temperature of $130^{\circ} \mathrm{C}$ for 24 hours. Then, samples were brought out in the desiccators and cooled for $10 \mathrm{~min}$. The initial moisture content of the samples $\omega_{0}$ was calculated based on wet basis according to Eq. (1) (Vitázek and Vereš, 2013):

$$
\omega_{0}=\left(1-\frac{m_{2}}{m_{1}}\right) \cdot 100, \%
$$

where:

$$
\begin{array}{ll}
\omega_{0} & \text { - initial moisture content, } \% \text { w.b. } \\
m_{1} & \text { - the initial mass of paddy, } g \\
m_{2} & \text { - the mass of paddy after drying, } g
\end{array}
$$

In the next stage, the samples were washed with the cold water so that the remaining foreign materials were removed. Then, soaking as the first step of parboiling process was performed at the temperature of $75^{\circ} \mathrm{C}$ for three hours. This is the gelatinization temperature of rice grain (Juliono, 1985; Chakraverty and Paul Singh, 2001). Afterwards, the samples were drained and divided to three sections, and the steaming stage was performed for the time durations of 10 , 20 and $30 \mathrm{~min}$. Steaming was performed using the methods of steam bath in autoclave under the pressure of $100 \mathrm{kPa}$. At the end of this stage, the samples were drained and spread on the absorber paper to remove the excessive water. The drying stage was carried out with two temperature levels of 45 and $60{ }^{\circ} \mathrm{C}$ by means of a laboratory oven. During the staying time in the oven, the moisture content of the samples was frequently measured using a digital moisture meter (GMK model 303RS, Korea) in order to attain the desired moistures of 8,10 and $12 \%$ (w.b.). After achieving of the desired moisture content, the samples were placed in the sealed polyethylene bags and left in a room with normal temperature to cool slowly for three hours. Then, the samples were placed to a refrigerator with a temperature of $4{ }^{\circ} \mathrm{C}$ to keep a constant moisture content of the samples. Before performing the milling process, the samples were brought out from the refrigerator and placed in the room with ambient temperature for three hours. Then, the samples were weighted by means of a digital balance to divide into groups of $50 \mathrm{~g}$ and consequently husked using a rubber roller husker (Satake Engineering Co., Ltd. Japan). After husking, the samples were weighted again and whitened by means of a laboratory whitener (model: JNMJ3). Finally, a laboratory separator was used for separating the head rice grains (at least $75 \%$ of the grain length) from broken grains. $H R Y$ was calculated according to Eq. (2):

$$
H R Y=\frac{m_{h}}{m_{p}} \cdot 100, \%
$$

where:

$m_{h} \quad$ - the mass of head rice, $g$

$m_{p} \quad$ - the initial mass of paddy sample, $\mathrm{g}$

To obtain the values of HRY for non-parboiled rice, separate experiments were performed for two levels of drying temperature $\left(45\right.$ and $60{ }^{\circ} \mathrm{C}$ ) and three levels of moisture content $(8,10$ and $12 \%)$.

The independent parameters included the paddy varieties Hashemi and Alikazemi (these varieties are the most popular in northern Iran), the steaming times of 10 , 20 and $30 \mathrm{~min}$, the drying temperatures of 45 and $60{ }^{\circ} \mathrm{C}$ and the paddy moisture content values of 8,10 and $12 \%$ (w.b.). The dependent variable was HRY. The experimental data were analysed using the analysis of variance (ANOVA). The statistical design utilized in analysing the data was a completely randomized design with a factorial arrangement of treatment. Duncan's Multiple-Range Test was used for the mean comparison of the effects at the probability level of $5 \%$ using SAS 9.0 software program.

\section{Results and discussion}

The results of the analysis of variance relating to $H R Y$ data (Table 2 ) revealed that all the main effects including variety $(V)$, drying temperature $(T)$, moisture content $(\omega)$ and steaming time $(t)$ had significant impacts on HRY. These results were consistent with the results of other researchers (Chakraverty and Paul Singh, 2001; Patindol et al., 2008; Kaddus Miah et al., 2011).

In addition, the dual interaction effects of $V / \omega, V / t, T / \omega$ and $\omega / t$ were significant on $H R Y$, while the interaction effects of $V / T$ and $T / t$ were not significant on $H R Y$. Except $V / T / t$, all triplet interaction effects were significant on $H R Y$. The interaction effect relating to four factors of $V / T / \omega / t$ was also significant. The mean comparison relating to the interaction effect of $V / T$ (Fig. 1a) showed that $H R Y$ increased for both varieties with increasing $T$ from 45 to $60^{\circ} \mathrm{C}$; however, it was not significant in Hashemi. The result is in contrast with the results of previous studies concerning raw rice (Zhang and Lan, 2007). Zhang and Lan (2007) in a study on the effect of drying temperature $\left(45\right.$ and $\left.60{ }^{\circ} \mathrm{C}\right)$ observed that the best

Table 1 Some physical and chemical properties of the tested varieties (non-parboiled grain)

\begin{tabular}{|l||c|c|c|c|c|}
\hline Variety & 1000-grain weight in g & Grain length in $\mathbf{~ m m}$ & Grain width in $\mathbf{~ m m}$ & Ratio of length to width & Amylose in \% \\
\hline Hashemi & 25 & 7.2 & 1.9 & 3.8 & 20.1 \\
\hline Alikazemi & 30 & 7.2 & 2.1 & 3.4 & 16.7 \\
\hline
\end{tabular}


Table 2 The analysis of variance relating to the independent parameters in paddy parboiling

\begin{tabular}{|c|c|c|}
\hline Variation sources & Degree of freedom & $H R Y$ \\
\hline Replication & 2 & $0.097^{\mathrm{ns}}$ \\
\hline Variety (V) & 1 & $191.574^{* *}$ \\
\hline Drying temperature $(T)$ & 1 & $1.527^{* *}$ \\
\hline Interactions $(V \cdot T)$ & 1 & $0.2133^{\mathrm{ns}}$ \\
\hline Moisture content $(\omega)$ & 2 & $12.449^{* *}$ \\
\hline Interactions $(\boldsymbol{V} \cdot \omega)$ & 2 & $1.759^{* *}$ \\
\hline Interactions $(\boldsymbol{T} \cdot \omega)$ & 2 & $1.318^{* *}$ \\
\hline Interactions $(V \cdot \omega \cdot T)$ & 2 & $0.880^{* *}$ \\
\hline Steaming time $(t)$ & 2 & $6.221^{* *}$ \\
\hline Interactions $(V \cdot t)$ & 2 & $1.847^{* *}$ \\
\hline Interactions $(T \cdot t)$ & 2 & $0.230^{\text {ns }}$ \\
\hline Interactions $(V \cdot T \cdot t)$ & 2 & $0.173^{\text {ns }}$ \\
\hline Interactions $(\omega \cdot t)$ & 2 & $0.603^{*}$ \\
\hline Interactions $(V \cdot \omega \cdot t)$ & 4 & $1.300^{* *}$ \\
\hline Interactions $(T \cdot \omega \cdot t)$ & 4 & $2.462^{* *}$ \\
\hline Interactions $(V \cdot T \cdot \omega \cdot t)$ & 4 & $1.450^{* *}$ \\
\hline Error & 78 & 0.294 \\
\hline Total & 107 & - \\
\hline
\end{tabular}

temperature for paddy drying is $45^{\circ} \mathrm{C}$. They mentioned that paddy drying at higher temperatures results in a sharp increase in thermal gradient and consequently the occurrence of cracks in the grain. The reason of this contradiction is related to the specific process of parboiling. Steaming in parboiling, with gelatinizing the grain and homogenizing its components, removes the cracks in the grain and consequently allows the application of higher temperature for drying in comparison to raw rice. This is one of the benefits of parboiling allowing the performance of faster milling, which leads to time savings.

For each tested variety, there were considerable differences in $H R Y$ on different levels of $\omega$ (Fig. 1b). For both varieties, the highest and lowest $H R Y$ s were obtained at $\omega$ : 8 and $10 \%$ (w.b.), respectively. The result is consistent with the previous research performed on the raw rice in which $\omega: 8 \%$ was introduced as optimal moisture content (Nasir Ahmadi et al., 2014). According to Fig. 1b, at $\omega: 12 \%$ higher HRY (66.301\%) was obtained than 10\% (65.095\%). It seems that two factors - higher milling recovery due to higher brittleness property in the grain at lower $\omega$ (factor $a$ ) and lower breakage due to higher hardness of the grain (factor b) - are effective on HRY (Kim et al., 2014). At $\omega: 8 \%$, both factors $(a \& b)$ and at $12 \%$, the factor of $b$ were determinant for enhancing of HRY. The moisture content of $10 \%$ was an intermediate state concerning the effectiveness of two factors $(a \& b)$.

In all tests of Hashemi variety, the considerable differences were observed for all levels of $t$ (Fig. 1c). For both varieties, the highest and lowest HRYs were obtained at $t 10$ and $30 \mathrm{~min}$, respectively. In Alikazemi variety, the level of 20 min did not differ from levels of 10 and 30 min in any significant way. On the other hand, the interaction effect of $V / t$ was more considerable in Hashemi variety than Alikazemi. Overall, $t: 10 \mathrm{~min}$ is introduced as an appropriate steaming time for parboiling of both varieties. The mean comparison results related to the interaction effect of $\omega / T$ on $H R Y$ (Fig. 2) revealed that in the experiments including $\omega$ : $8 \%$, the highest $H R Y$ was achieved at $T: 45^{\circ} \mathrm{C}$; however, the difference between the levels was not significant.

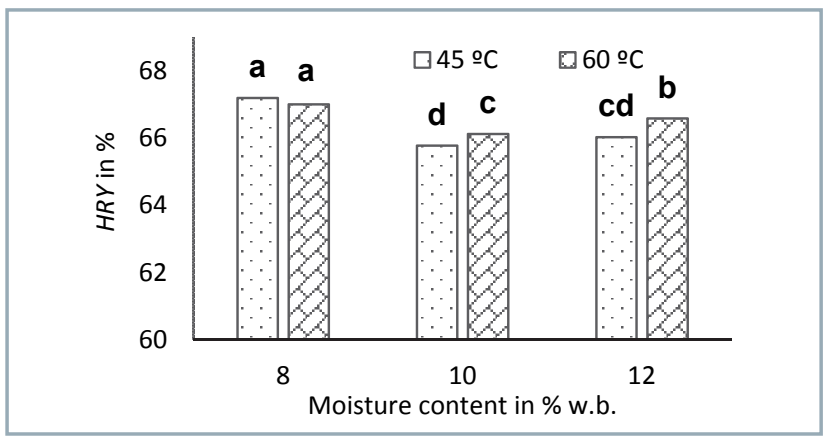

Fig. 2 The mean comparison related to the interaction effect of $V / T$ on HRY

The different letters indicate the significant differences $(P<0.05)$. The letters $a$ and $d$ indicate the highest and lowest means, respectively

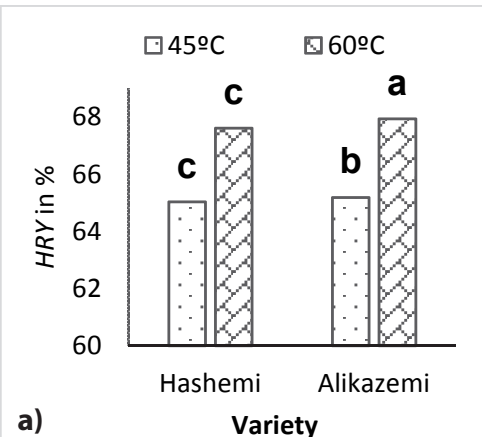

a)

Variety
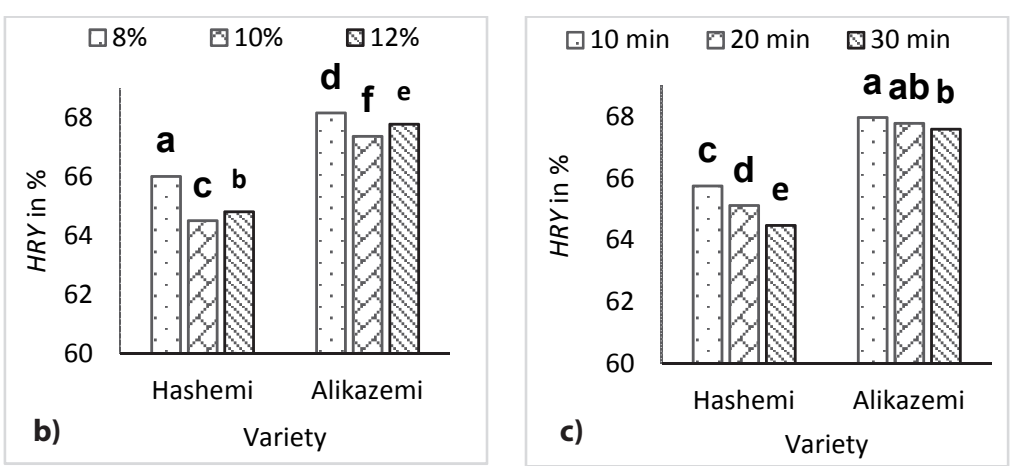

Fig. 1 Mean comparison results related to the interaction effect of $V$ with a) $T$, b) $\omega$ and c) $t$ on $H R Y$ The different letters indicate the significant differences between the effects $(P<0.05)$. The letters $a$ and $f$ indicate the highest and lowest means, respectively 
In the experiments including both $\omega: 10$ and 12\%, increasing in $T$ from 45 to $60{ }^{\circ} \mathrm{C}$ resulted in a significant increase in $H R Y$. However, there is no difference (statistically) between $\mathrm{T}: 45^{\circ} \mathrm{C}$ and $60{ }^{\circ} \mathrm{C}$ at the moisture level of $8 \%$. This means that at $\omega$ higher than $8 \%$ (w.b.), increase in temperature causes an increase in the grain strength. In addition to the description given for Fig. 1a (about the gelatinization of grain under the impression of steaming), at $\omega: 8 \%$, the grain is not able to endure simultaneously stresses due to the high $T$ and low $\omega$. Therefore, at this moisture level, $H R Y$ did not increase with increasing $T$, similarly to the other moisture levels.

According to Fig. 3, increasing $t$ from 10 to 30 min caused a significant decrease in $H R Y$ for all levels of $\omega$. However, the level of $20 \mathrm{~min}$ did not differ from the levels of 10 and $30 \mathrm{~min}$ in any considerable way. As a result, $t: 10 \mathrm{~min}$ is an optimal time for paddy parboiling when $\omega$ is set between 8 and $12 \%$.

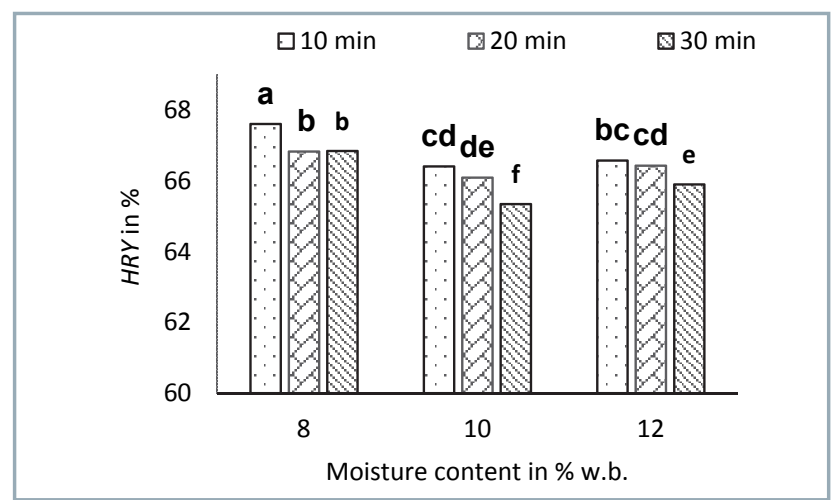

Fig. 3 Mean comparison results related to the interaction effect of $\omega / t$ on HRY

The different letters indicate the significant differences $(P<0.05)$. The letters $a$ and $f$ indicate the highest and lowest means, respectively
The result was obtained earlier in surveying the interaction effect of $\omega / t$.

The mean comparison results related to the interaction effects of $V / T / \omega$ on $H R Y$ were given in Table 3. It is revealed that in Hashemi variety and at $T: 45^{\circ} \mathrm{C}$, increasing $\omega$ resulted in decreasing $H R Y$. This decrease at the levels of $8 \%$ and $10 \%$ was very significant.

Overall, in all levels of $V$ and $T$, the highest and lowest values of $H R Y$ were obtained at $\omega: 8 \%$ and $10 \%$, respectively, and the value of $12 \%$ has shown an intermediate status. As it was mentioned earlier, $\omega: 10 \%$ does not show the brittleness property as high as paddy wih $\omega: 8 \%$. In addition, the occurrence rate of hidden cracks in the paddy with higher $\omega(12 \%)$ is lower due to lower stress of dehydration. The highest $H R Y$ for Hashemi variety at $T: 60^{\circ} \mathrm{C}$ was achieved at $\omega: 8 \%$; however, it does not differ from the value obtained at $T: 45^{\circ} \mathrm{C}$ in any significant way. For Alikazemi variety, the highest $H R Y$ was achieved at $T: 45^{\circ} \mathrm{C}$ and at $\omega: 8 \%$. According to Table 3, if using paddy with $\omega: 10 \%$, better $H R Y$ result was achieved at $T: 60^{\circ} \mathrm{C}$ for Alikazemi variety; however, in Hashemi variety, changing Thas not any significant effect on $H R Y$. The mean comparison results related to the interaction effects $\mathrm{V} / \omega / \mathrm{t}$ on $H R Y$ are given in Table 4.

In Hashemi variety, the highest and lowest HRYs were achieved at $t: 10$ and 30 min, respectively, for all levels of $\omega$. In Alikazemi variety and at $\omega: 8 \%$, a significant difference among HRYs was not observed; however, the highest $H R Y$ was achieved at $t: 10 \mathrm{~min}$. At $\omega: 10 \%$, the $H R Y$ values were almost identical and a significant difference was observed only between the levels of $10(67.737 \%)$ and $20 \mathrm{~min}$ $(67.145 \%)$. At moisture of $12 \%, H R Y_{s}$ have not shown any significant difference between $t: 10$ and $20 \mathrm{~min}$. The lowest $H R Y$ was achieved at $t: 30 \mathrm{~min}$.

The interaction effects related to three factors of $T / \omega / t$ (Table 5) showed that the highest $H R Y$ value (67.972\%) was

Table 3 The mean comparison related to the interaction effect of $V / T / \omega$ on $H R Y$

\begin{tabular}{|c|c|c|c|c|c|c|c|}
\hline Variety & $T$ in ${ }^{\circ} \mathrm{C}$ & $\omega$ in \% w.b. & $H R Y$ in \% & Variety & $T$ in ${ }^{\circ} \mathrm{C}$ & $\omega$ in \% w.b. & $H R Y$ in \% \\
\hline \multirow{2}{*}{ Hashemi } & 45 & $\begin{array}{c}8 \\
10 \\
12\end{array}$ & $\begin{array}{l}66.011^{\mathrm{e}} \\
64.557^{\mathrm{g}} \\
64.577^{\mathrm{g}}\end{array}$ & \multirow{2}{*}{ Alikazemi } & 45 & $\begin{array}{c}8 \\
10 \\
12\end{array}$ & $\begin{array}{l}68.366^{a} \\
66.996^{d} \\
67.488^{c}\end{array}$ \\
\hline & 60 & $\begin{array}{c}8 \\
10 \\
12\end{array}$ & $\begin{array}{l}66.022^{e} \\
64.476^{g} \\
65.073^{f}\end{array}$ & & 60 & $\begin{array}{c}8 \\
10 \\
12\end{array}$ & $\begin{array}{l}68.087^{a b} \\
67.760^{b c} \\
67.982^{a b}\end{array}$ \\
\hline
\end{tabular}

The different letters indicate the significant differences $(P<0.05)$. The letters a and $\mathrm{g}$ indicate the highest and lowest means, respectively

Table 4 The mean comparison related to the interaction effect of $V / \omega / t$ on $H R Y$

\begin{tabular}{|c|c|c|c|c|c|c|c|}
\hline Variety & $\omega$ in \% w.b. & $t$ in $\min$ & $H R Y$ in \% & Variety & $\omega$ in \% w.b. & $t$ in $\min$ & $H R Y$ in \% \\
\hline \multirow{3}{*}{ Hashemi } & 8 & $\begin{array}{l}10 \\
20 \\
30\end{array}$ & $\begin{array}{l}66.952^{c} \\
65.612^{d} \\
65.487^{\text {de }}\end{array}$ & \multirow{3}{*}{ Alikazemi } & 8 & $\begin{array}{l}10 \\
20 \\
30\end{array}$ & $\begin{array}{l}68.260^{a} \\
68.053^{a} \\
68.208^{a}\end{array}$ \\
\hline & 10 & $\begin{array}{l}10 \\
20 \\
30\end{array}$ & $\begin{array}{l}65.077^{\text {ef }} \\
65.035^{\text {ef }} \\
63.437^{\text {h }}\end{array}$ & & 10 & $\begin{array}{l}10 \\
20 \\
30\end{array}$ & $\begin{array}{c}67.737^{a b} \\
67.145^{c} \\
67.252^{b c}\end{array}$ \\
\hline & 12 & $\begin{array}{l}10 \\
20 \\
30\end{array}$ & $\begin{array}{l}65.240^{\text {de }} \\
64.713^{\text {fg }} \\
64.492^{g}\end{array}$ & & 12 & $\begin{array}{l}10 \\
20 \\
30\end{array}$ & $\begin{array}{l}67.907^{a} \\
68.147^{a} \\
67.308^{b c}\end{array}$ \\
\hline
\end{tabular}

The different letters indicate the significant differences $(P<0.05)$. The letters $a$ and $g$ indicate the highest and lowest means, respectively 
Table 5 The mean comparison related to the interaction effect of $T / \omega / t$ on $H R Y$

\begin{tabular}{|c|c|c|c|c|c|c|c|}
\hline$T$ in ${ }^{\circ} \mathrm{C}$ & $\omega$ in \% w.b. & $t$ in $\min$ & $H R Y$ in \% & $T$ in ${ }^{\circ} \mathrm{C}$ & $\omega$ in \% w.b. & $t$ in $\min$ & $H R Y$ in \% \\
\hline \multirow{3}{*}{45} & 8 & $\begin{array}{l}10 \\
20 \\
30\end{array}$ & $\begin{array}{c}67.972^{\mathrm{a}} \\
66.738^{\mathrm{cde}} \\
66.855^{\mathrm{bcd}}\end{array}$ & \multirow{3}{*}{60} & 8 & $\begin{array}{l}10 \\
20 \\
30\end{array}$ & $\begin{array}{l}67.240^{b c} \\
66.927^{b c d} \\
66.840^{b c d}\end{array}$ \\
\hline & 10 & $\begin{array}{l}10 \\
20 \\
30\end{array}$ & $\begin{array}{c}66.682^{\text {def }} \\
65.620^{j} \\
65.027^{k}\end{array}$ & & 10 & $\begin{array}{l}10 \\
20 \\
30\end{array}$ & $\begin{array}{c}66.132^{\text {ghij }} \\
66.560^{\text {defg }} \\
65.662^{i j}\end{array}$ \\
\hline & 12 & $\begin{array}{l}10 \\
20 \\
30\end{array}$ & $\begin{array}{c}65.827^{\text {hij }} \\
66.613^{\text {defg }} \\
65.627^{j}\end{array}$ & & 12 & $\begin{array}{l}10 \\
20 \\
30\end{array}$ & $\begin{array}{c}67.320^{\mathrm{b}} \\
66.247^{\text {ffgh }} \\
66.173^{\text {fghi }}\end{array}$ \\
\hline
\end{tabular}

The different letters indicate the significant differences $(P<0.05)$. The letters $a$ and $k$ indicate the highest and lowest means, respectively

obtained at $T: 45^{\circ} \mathrm{C}, t: 10 \mathrm{~min}$ and $\omega: 8 \%$. This is followed by the combination including $T: 60^{\circ} \mathrm{C}, \omega: 12 \%$ and $t: 10 \mathrm{~min}$ which has shown the second highest $H R Y$ value (67.320\%). The combination including the $T: 60^{\circ} \mathrm{C}, \omega: 8 \%$ and $t: 10 \mathrm{~min}$ has shown the third highest $H R Y$ value (67.240\%). Overall, the steaming time of 10 min had the most positive impact on $H R Y$ in all combinations including $T$ and $\omega$. Although in a few cases higher $H R Y$ were achieved at the steaming time of $20 \mathrm{~min}$ than $10 \mathrm{~min}$, the difference was not significant.

The mean comparison results related to the interaction effect of four factors including $V / T / \omega / t$ (Table 6) showed that the highest $H R Y(68.647 \%)$ was achieved in Alikazemi variety, at $T: 45^{\circ} \mathrm{C}, t: 10 \mathrm{~min}$ and $\omega: 8 \%$. The combination of Alikazemi $/ 45^{\circ} \mathrm{C} / 12 \% / 20$ min showed the second highest $H R Y$ value (68.507\%). The combination including Alikazemi variety has proved to have higher $H R Y$ than the combination including Hashemi variety. For Hashemi variety, the highest $\operatorname{HRY}(67.297 \%)$ was achieved at $T: 45^{\circ} \mathrm{C}, t: 10 \mathrm{~min}$ and $\omega: 8 \%$.
The combination of Hashemi/ $60{ }^{\circ} \mathrm{C} / 8 \% / 10$ min showed the second highest $H R Y(66.607 \%)$.

At $T: 45{ }^{\circ} \mathrm{C}$ and at both $\omega: 8 \%$ and $12 \%$, the highest $H R Y$ values were obtained at $t: 10 \mathrm{~min}$ in Hashemi variety. Although $t: 30$ min showed higher HRY than $20 \mathrm{~min}$, the differences were not significant. However, at $\omega: 10 \%$, the mean of $H R Y$ significantly decreased with increasing $t$ from $10 \mathrm{~min}$ to $30 \mathrm{~min}$. In the experiments including Hashemi variety, $\mathrm{T}: 60^{\circ} \mathrm{C}$ and $\omega: 8 \%, H R Y$ decreased with increasing $t$. In the same combination, but including $\omega: 10 \%$, the highest $H R Y$ was obtained at $t: 20 \mathrm{~min}$; however, it does not differ from $t: 10 \mathrm{~min}$ in any significant way. As a result, in this combination $t: 10 \mathrm{~min}$ had contributed towards the best value of $H R Y$. For Alikazemi variety at $T: 45^{\circ} \mathrm{C}$ and $\omega: 8 \%$, the significant differences were not observed among the levels of $t$; however, the highest $H R Y$ was achieved at $t: 10$ min. At $\omega: 10 \%$, the highest $H R Y$ was obtained at $t: 10$ min as well. At $\omega: 12 \%$, the highest $H R Y$ was observed at $t: 20 \mathrm{~min}$.

Table 6 The mean comparison relating to the interaction effect of $V / T / M / t$ on $H R Y$

\begin{tabular}{|c|c|c|c|c|c|c|c|c|c|}
\hline Variety & $T$ in ${ }^{\circ} \mathrm{C}$ & $\omega$ in \% & $t$ in $\min$ & $H R Y$ in \% & Variety & $T$ in ${ }^{\circ} \mathrm{C}$ & $\omega$ in \% & $t$ in $\min$ & $H R Y$ in \% \\
\hline \multirow{18}{*}{ Hashemi } & \multirow{9}{*}{45} & \multirow{3}{*}{8} & 10 & $67.297^{\mathrm{efg}}$ & \multirow{18}{*}{ Alikazemi } & \multirow{9}{*}{45} & \multirow{3}{*}{8} & 10 & $68.647^{\mathrm{a}}$ \\
\hline & & & 20 & $65.247^{1 \mathrm{mno}}$ & & & & 20 & $68.230^{\mathrm{abcd}}$ \\
\hline & & & 30 & $65.490^{\mathrm{klmn}}$ & & & & 30 & $68.220^{\mathrm{abcd}}$ \\
\hline & & \multirow{3}{*}{10} & 10 & $65.717^{\mathrm{jklm}}$ & & & \multirow{3}{*}{10} & 10 & $67.647^{\text {cdef }}$ \\
\hline & & & 20 & $64.950^{\text {nopq }}$ & & & & 20 & $66.290^{\mathrm{ij}}$ \\
\hline & & & 30 & $63.003^{s}$ & & & & 30 & $67.050^{\text {fgh }}$ \\
\hline & & \multirow{3}{*}{12} & 10 & $64.260^{\text {qr }}$ & & & \multirow{3}{*}{12} & 10 & $67.393^{\mathrm{ef}}$ \\
\hline & & & 20 & $64.720^{\circ p q}$ & & & & 20 & $68.507^{\mathrm{ab}}$ \\
\hline & & & 30 & $64.690^{\mathrm{opq}}$ & & & & 30 & $66.563^{\mathrm{hi}}$ \\
\hline & \multirow{9}{*}{60} & \multirow{3}{*}{8} & 10 & $66.607^{g h i}$ & & \multirow{9}{*}{60} & \multirow{3}{*}{8} & 10 & $67.873^{\text {abcde }}$ \\
\hline & & & 20 & $65.977^{\mathrm{ijkl}}$ & & & & 20 & $67.877^{\text {abcde }}$ \\
\hline & & & 30 & $65.483^{\mathrm{klmn}}$ & & & & 30 & $68.197^{\mathrm{abcd}}$ \\
\hline & & \multirow{3}{*}{10} & 10 & $64.437^{\text {pqr }}$ & & & \multirow{3}{*}{10} & 10 & $67.827^{\text {bcde }}$ \\
\hline & & & 20 & $65.120^{\text {mnop }}$ & & & & 20 & $68.000^{\mathrm{abcde}}$ \\
\hline & & & 30 & $63.870^{r}$ & & & & 30 & $67.453^{\text {def }}$ \\
\hline & & \multirow{3}{*}{12} & 10 & $66.220^{\mathrm{ijk}}$ & & & \multirow{3}{*}{12} & 10 & $68.420^{\mathrm{abc}}$ \\
\hline & & & 20 & $64.707^{o p q}$ & & & & 20 & $67.787^{\text {bcdef }}$ \\
\hline & & & 30 & $64.293^{\mathrm{qr}}$ & & & & 30 & $68.053^{\text {abcde }}$ \\
\hline
\end{tabular}

The different letters indicate the significant differences $(P<0.05)$. The letters $a$ and $s$ indicate the highest and lowest means, respectively 
It is noteworthy that in all experiments including Alikazemi, T: $45^{\circ} \mathrm{C}$ and at all levels of $\omega$, the lowest $H R Y$ values were achieved at $t: 30 \mathrm{~min}$. In the experiments including Alikazemi, $\omega: 8 \%$ and $T: 60^{\circ} \mathrm{C}$, the results similar to values achieved at $T: 45^{\circ} \mathrm{C}$, therefore, the significant differences between the individual of $t$ had not been observed. This case was true for $\omega: 10$ and $12 \%$. Considering the results, the increasing of $t$ levels from 10 to 30 min has not shown significant impacts on $H R Y$ in Alikazemi variety and at $t$ : $60^{\circ} \mathrm{C}$ and all levels of $\omega$.

\section{Comparison between $H R Y$ obtained from raw rice and parboiled rice}

The mean of $H R Y$ for Hashemi variety at all levels of drying temperature and moisture content were compared in Fig. 4. The results indicate that in all experiments, the values of $H R Y$ related to the parboiled rice $\left(H R Y_{p}\right)$ were considerably higher than the values of $H R Y$ of raw rice $\left(H R Y_{r}\right)$. At $T: 45^{\circ} \mathrm{C}$, there were the increases of 34,24 and $21 \%$, respectively for the moisture levels of 8,10 and $12 \%$ in $H R Y_{p}$ in comparison to $H R Y_{r}$. Corresponding values in $T: 60^{\circ} \mathrm{C}$ were 33,31 and $34 \%$. Therefore, the highest increase in $H R Y_{p}$ in comparison to $H R Y_{r}$ was observed at $\omega: 8 \%$, which is common in the milling factories.

The results of experiments for Alikazemi variety showed that a considerable increase in $H R Y_{p}$ in comparison to $H R Y_{r}$ (Fig. 5). At $45{ }^{\circ} \mathrm{C}, H R Y_{p}$ increased by 46,43 and $43 \%$ in comparison to $H R Y_{r}$, for $\omega: 8,10$ and $12 \%$, respectively. Corresponding values at T: $60{ }^{\circ} \mathrm{C}$ were 54, 55 and $59 \%$. Therefore, the highest increase in $H R Y_{p}$ in comparison to $H R Y_{r}$ was obtained at $\omega: 8$ and $12 \%$, respectively for $T: 45$ and $60^{\circ} \mathrm{C}$. As a result, the parboiling process plays a much more important role in relation to $H R Y$ for Alikazemi variety than Hashemi.

For Hashemi variety, the best $H R Y_{p}(67.297 \%)$ was obtained in the treatment combination of $45^{\circ} \mathrm{C} / 8 \% / 10 \mathrm{~min}$ and the best $H R Y_{r}(53.49 \%)$ in the combination of $45^{\circ} \mathrm{C} / 12 \%$. Considering the values of $H R Y_{p}$ and $H R Y_{r}$, it is concluded that for Hashemi variety, parboiling causes an increase of $25.8 \%$ in $H R Y$. For Alikazemi, the best $H R Y_{p}(68.647 \%)$ was obtained in the treatment combination of $45^{\circ} \mathrm{C} / 8 \% / 10 \mathrm{~min}$ and the best $H R Y_{r}(47.91 \%)$ in the combination of $45^{\circ} \mathrm{C} / 12 \%$. Considering the values of $H R Y_{p}$ and $H R Y_{r}$ it is concluded that for Alikazemi variety, parboiling causes an increase of $43.3 \%$ in $H R Y$.

\section{Conclusions}

The time of $10 \mathrm{~min}$ was introduced as the most appropriate steaming time for parboiling of tested varieties from both aspects of milling quality and energy consumption. Optimal $T$ for parboiled rice is $60{ }^{\circ} \mathrm{C}$, while it is $45^{\circ} \mathrm{C}$ for raw rice. In other words, parboiling with gelatinizing of the grain and homogenizing its components allows the application of higher drying temperature than non-parboiled rice. In Hashemi variety, changes in $T$ (between 45 and $60^{\circ} \mathrm{C}$ ) have not shown any significant effects on HRY. Therefore, higher $T s\left(60{ }^{\circ} \mathrm{C}\right)$ are proposed due to time saving. The combinations including Alikazemi variety had higher $H R Y$ in the most cases in comparison to Hashemi variety. Of all experiments, the highest $H R Y(68.647 \%)$ was achieved in the treatment combination of Alikazemi $/ 45^{\circ} \mathrm{C} / 10 \mathrm{~min} / 8 \%$. For Hashemi variety, the highest $H R Y(67.297 \%)$ was achieved in the combination of $45^{\circ} \mathrm{C} / 10 \mathrm{~min} / 8 \%$. If the appropriate treatment combinations concerning $H R Y_{p}$ and $H R Y_{r}$ are
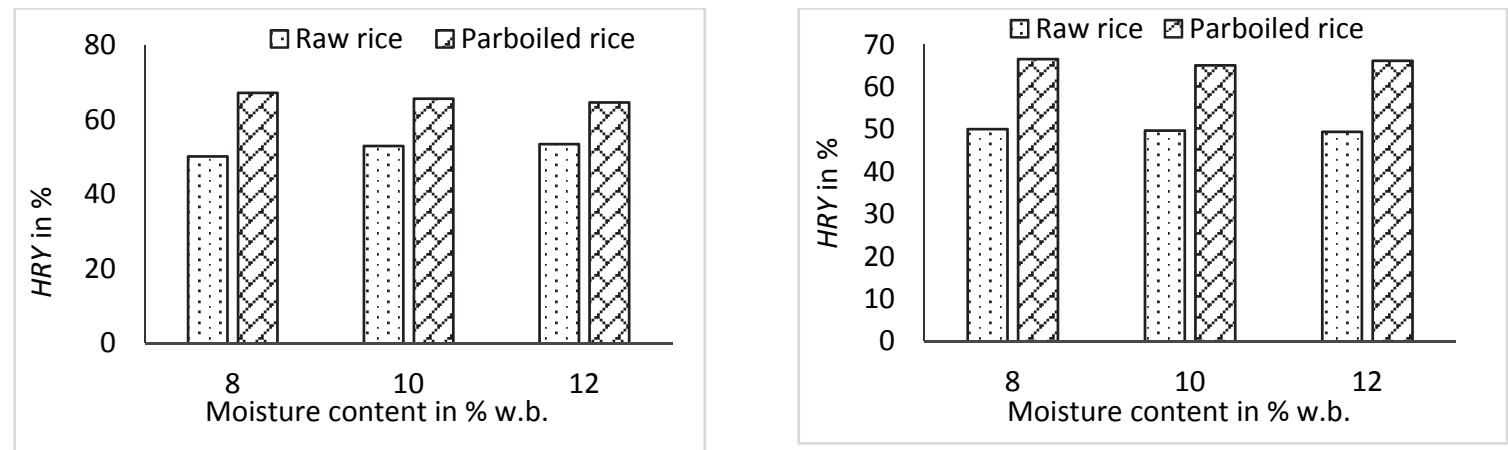

Fig. 4 The mean of $H R Y$ for Hashemi at different levels of $\omega$ and $T:$ a) 45 and b) $60^{\circ} \mathrm{C}$
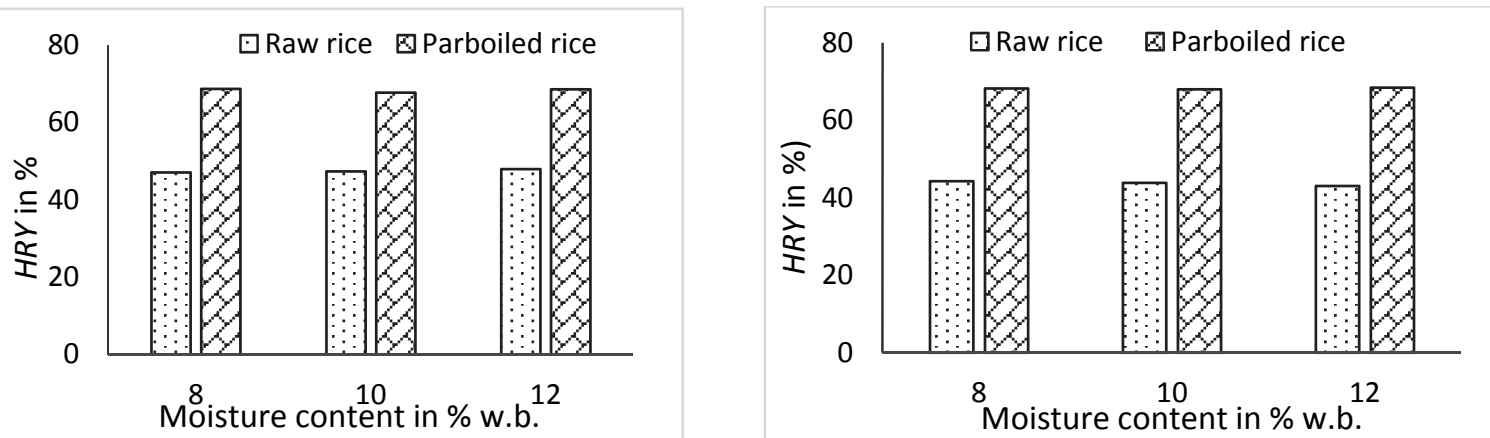

Fig. 5 The mean of $H R Y$ for Alikazemi at the different levels of $\omega$ in $T: a) 45$ and b) $60^{\circ} \mathrm{C}$ 
selected, parboiling causes an increase of $25.8 \%$ in $H R Y$. This value is $43.3 \%$ for Alikazemi variety.

\section{References}

ASAE Standards S352. 2. 2000. Moisture measurement - Unground grain and seeds.

CHAKRAVERTY, A. - PAUL SINGH, R. 2001. Postharvest Technology: Cereals, Pulses, Fruits and Vegetables. New York: Science Publishers, 356 pp. ISBN 9781578081684.

DA FONSECA, F. A. - SOARES JUNIOR, M. S. - CALIARI, M. BASSINELLO, P. Z. - DA COSTA EIFERT, E. - GARCIA, D. M. 2011 Changes occurring during the parboiling of upland rice and in the maceration water at different temperatures and soaking times. In International Journal of Food Science Technology, vol. 46, no. 9, pp. 1912-1920.

IMONIGIE, P. S. - YUSUF, K. A. - ATANDA, E. O. 2017. Development of a temperature-controlled paddy rice parboiler. In American Journal of Mechanical and Materials Engineering, vol. 1, pp. 5-9.

JAGTAP, P. S. - SUBRAMANIAN, R. - SINGH, V. 2008. Influence of soaking on crushing strength of raw and parboiled rice. In International Journal of Food Properties, vol. 11, no. 1, pp. 127-136. JULIONO, O. 1985. Rice: chemistry and technology. American Associate Cereals Chemists. IMC, pp. 385-411.

KADDUS MIAH, M. A. - ANWARUL HAQUE, M. - DOUGLASS, P. CLARKE, B. 2011. Parboiling of rice, Part I: Effect of hot soaking time on quality of milled rice. In International Journal of Food Science Technology, vol. 37, pp. 527-537.
KIM, O. W. - KIM, H. - LEE, H. J. 2014. Impact of moisture content on milling characteristics of short-grain rice. In Applied Engineering Agriculture, vol. 30, no. 6, pp. 927-933.

KWOFIE, E. M. - NGADI, M. 2017. A review of rice parboiling systems, energy supply, and consumption. In Renewable Sustainable Energy Reviews, vol. 72, pp. 465-472.

NASIR AHMADI, A. - EMADI, B. - ABBASPOUR FARD, M. H. AGHAGHOLZADE, H. 2014. Influence of moisture content, variety and parboiling on milling quality of rice grains. In Rice Science, vol. 20, pp. 116-122.

OYEDELE, O. A. - ADEOTI, O. 2013. Investigation into the optimum moisture content and parboiling time for milling Igbemo rice. In Journal of Rice Research, vol. 1, no. 1, pp. 1-3.

PATINDOL, J. - NEWTON, J. - WANG, Y. J. 2008. Functional properties as affected by laboratory scale parboiling of rough rice and brown rice. In Journal of Food Science, pp. 370-377.

PILLAIYAR, P. 1981. Household parboiling of parboiled rice. In Kishan World, vol. 8, no. 20-21.

VITÁZEK, I. - VEREŠ, P. 2013. Drying rate of grain maize. In Acta Technologica Agriculturae, vol. 16, no. 2, pp. 20-21.

ZHANG, X. - LAN, Y. 2007. Effect of drying temperature and moisture content on rice taste quality. In Agricultural Engineering, International CIGR eJournal, Manuscript FP07 023, vol. IX. 